\title{
Mehr als nur Technik
}

Liebe Leserin, lieber Leser,

ein ereignisreiches Jahr 2015 liegt hinter uns. Vielleicht nutzen Sie die ruhigen Tage bis zum neuen Jahr, um nicht nur die Dezemberausgabe, sondern alle ATZelektronik-Ausgaben dieses Jahres nochmal durchzublättern und einige Ereignisse Revue passieren zu lassen. Denn einige Veröffentlichungen dokumentieren den Wandel, den die Autoindustrie in den letzten Monaten intensiv durchlaufen hat. Traditionsgemäß finden Sie Best-practice-Artikel aus allen Bereichen der Fahrzeugelektronik, allerdings mit deutlicher Tendenz zu Hochvoltsystemen, einem neu zu organisierenden Zweispannungsbordnetz, IT- und Softwarethemen sowie zu Innovationen aus der Consumer-Elektronik.

Best-practice-Artikel mit technischer Tiefe bilden bekanntermaßen das Grundgerüst der ATZelektronik. Die Dokumentation von Fortschritten wurde aber auch von kritischen Autorenbeiträgen ergänzt, die an Ausdruckskraft im Vergleich zu den Vorjahren gewonnen haben - motiviert durch intensive Hintergrundgespräche, die auch die Redaktion für meinungsbildende Eigenbeiträge und Interviews nutzen konnte.

Somit steuern wir gemeinsam in das Jahr 2016, in dem die Brisanz derselben Themen zunehmen wird: Die Diskussion um die Realisierungschancen von PostLithium-Akkumulatoren und energiereicheren Lithium-Ionen-Batterien muss unbedingt an Qualität gewinnen. Ebenso das Thema IT-Security für vernetzte Fahrzeuge. In diesem Zusammenhang wird es weiterhin sehr spannend sein, wie und mit welchen IT-Unternehmen und Digitalisierungsprogrammen sich die Autohersteller nachhaltig positionieren können. Kryptografie, die möglichst sichere Datenverschlüsselung und die Auswirkungen auf künftige Bordnetze zählen deshalb zu den neuen Schwerpunkten der ATZelektronik in 2016.
Wie in den 2015er-Ausgaben zu lesen, stellen einige Experten die funktionale Sicherheit von Fahrerassistenzsystemen, die eine Hochautomatisierung ermöglichen sollen, aufgrund nicht zukunftsfähiger Entwicklungs- und Testmethoden infrage. Dasselbe gilt auch für die Softwareentwicklung. Mit diesen Experten und Zeitzeugen sollte man im kommenden Jahr diskutieren, gerne auf der Plattform der ATZelektronik.

Unsere gemeinsamen Publikationen sind das Spiegelbild der Dinge, die die Branche bewegen. Allerdings ist das Bild nicht vollständig. Denn technische Artikel allein projizieren nur einen Teilbereich. Wir zoomen deswegen heraus, im Sinne eines guten Technologiemarketings, das Ingenieuren mehr Orientierung gibt. Dieses Konzept ist gut angenommen worden, es ist aber zugegebenermaßen ausbaufähig. Wir müssen internationaler werden. Was geschieht beispielsweise hinter den Kulissen im Silicon Valley oder in China? Die Ausgabe 1/2016 wird Ihnen erste Beweise für diese Ausbaustufe liefern - inhaltlich ebenso wie von unserem Publikationskonzept. Lassen Sie sich überraschen.

Frohe Weihnachten wünscht Ihnen,

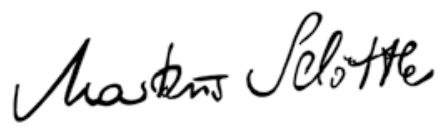

Markus Schöttle

Stellvertretender Chefredakteur

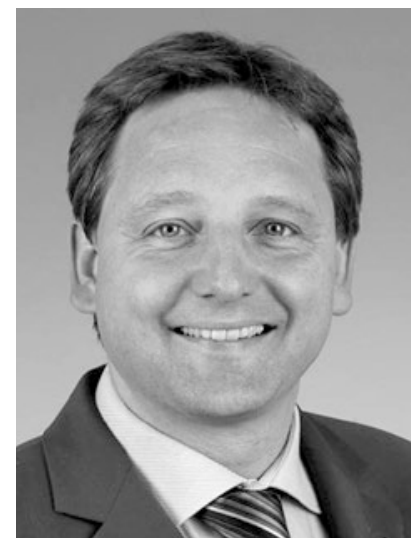

Mieten

\section{statt kaufen?}

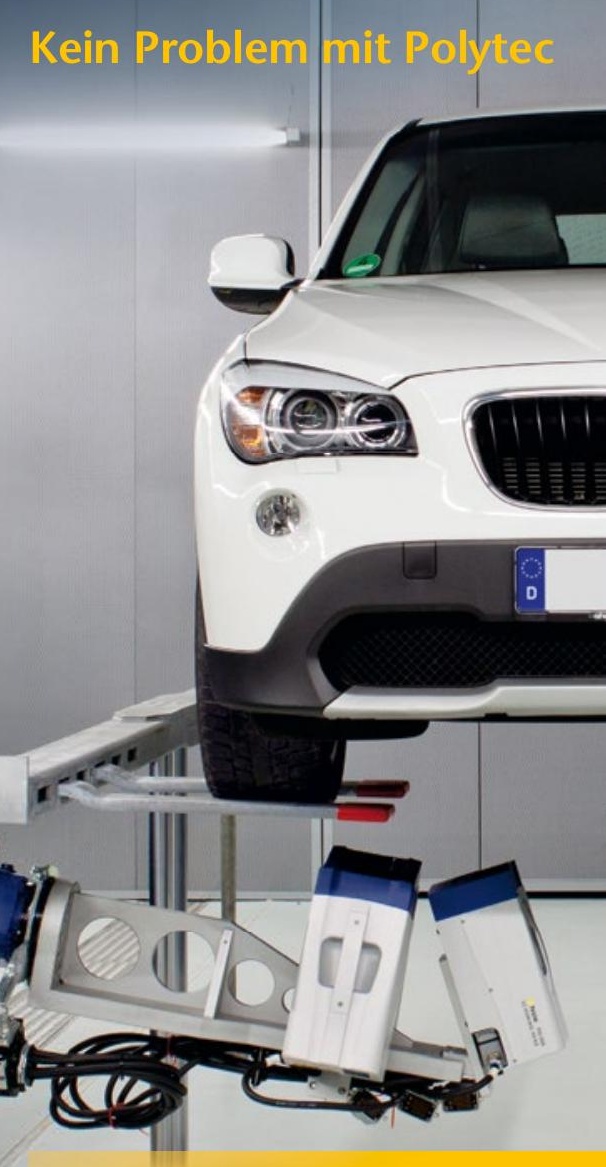

Sie haben kurzfristig oder gelegentlich anfallende Messaufgaben? Dann nutzen Sie einfach den Polytec-Service: Im hochmodernen Test-Center in Waldbronn steht Ihnen die weltweit leistungsfähigste Messanlage zur vollautomatischen Schwingungsmessung zur Verfügung. Oder Sie lassen direkt bei Ihnen vor Ort messen. Vom Einzelbaustein bis zum vollen Programm inklusive Ingenieurteam ist alles machbar.

Mehr unter: www.polytec.de/service 